\title{
EDITORIAL: FORMAÇÃO DE PROFESSORES, EDUCAÇÃO E PSICANÁLISE
}

A presente edição da ETD traz o dossiê "Psicanálise, educação e formação de professores" como mais uma contribuição à reflexão sobre a inquietante tarefa de educar. Freud ([1919]1964b), precisamente um século atrás, remeteu o inquietante ao que nos é absolutamente familiar, evidenciando que ele é constitutivo e está entranhado em nós, embora espraiado na externalidade como o estranho fora de nós. Luz e sombra, portanto, alternam-se, confundem-se, criam formas que se apresentam a nossos olhos para reconhecimento e decifração, como na imagem proposta em nossa capa e nos artigos do dossiê.

É também de Freud (1975), em carta endereçada a Lou Andreas Salomé, a afirmação citada por Bion (1977, p. 59), em seu texto "Cesura", de que "tenho que artificialmente cegarme, a fim de focalizar toda luz num ponto escuro" ${ }^{3}$. Onde a luz se apresenta timidamente, é preciso a total escuridão para que ela se faça visível. Quando a luz branca dos refletores do discurso bem-acabado, da teoria fechada e da instrumentalização técnica é lançada exuberante sobre a realidade, ela elimina nuanças, incertezas, sombras, impedindo-nos de fazer esse exercício. Esse é o paradoxo com o qual devemos trabalhar. Se na luz imaginamos saber o que vemos, é na sombra e na escuridão que aguçamos os sentidos, resgatando-os do adormecimento. No interjogo luz e sombra tornamo-nos observadores daquilo de cuja existência sequer ousamos suspeitar; capacitamo-nos a escutar ondas de som antes inaudíveis ou captar luz onde antes só se supunha escuridão.

Está aí o porquê de um dossiê sobre educação e formação de professores, que tem a psicanálise como campo de interlocução privilegiado. A ciência criada por Freud nos convoca

\footnotetext{
${ }^{1}$ Doutora em Educação - Universidade Estadual de Campinas (UNICAMP) - Campinas, SP - Brasil. Professora de Psicologia Educacional - Faculdade de Educação - Universidade Estadual de Campinas (UNICAMP) - Campinas, SP - Brasil. Membro Filiado da Sociedade Brasileira de Psicanálise de São Paulo (SBPSP). Membro da Association for the Psychoanalysis of Culture \& Society (APCS). E-mail: ana.archangelo@gmail.com

${ }^{2}$ Doutora em Linguística - Universidade Estadual de Campinas (UNICAMP) - Campinas, SP - Brasil. Livre Docente em Educação, sub-área Educação de Surdos e Libras Universidade Estadual de Campinas (UNICAMP) - Campinas, SP - Brasil. Mestre em Psicologia Clínica (PUCCAMP). Representante da UNICAMP no NEPI da AUGM (Uruguai). Docente da Faculdade de Educação - Universidade Estadual de Campinas (UNICAMP) - Campinas, SP - Brasil. Email: reginalaghi@uol.com.br

${ }^{3}$ No original: "[...] I have to blind myself artificially in order to focus all the light on one dark spot".
}

(C) ETD- Educação Temática Digital Campinas, SP $\quad$ v.21 $\quad$ n.2 $\quad$ p.285-287 abr./jun. 2019 
a operar com os paradoxos, (re)conhecer o desconhecido, sustentar a incerteza, aquilo que se apresenta a despeito de a luz da consciência não permitir facilmente identificar. A psicanálise nos obriga a aguçar os sentidos para aquilo que se esconde e se mostra. Mas não se trata de tarefa fácil.

O Homem dos Lobos ${ }^{4}$, em My recollections of Sigmund Freud (GARDINER, 1973, p. 140, tradução livre), a certa altura, ao falar de sua imersão no tratamento e na própria teoria psicanalítica, discorre sobre como Freud e ele concebiam a capacidade de compreender a psicanálise.

\begin{abstract}
Nós falávamos sobre quão difícil é, para uma pessoa saudável, aceitar os princípios dos ensinamentos de Freud, uma vez que eles ferem sua vaidade. É diferente para o neurótico que tem, antes de mais nada, experimentado em sua própria pessoa a força e os objetivos de seus impulsos inconscientes e, secundariamente, submetendo-se à psicanálise, toma ciência de sua inabilidade para manejá-los sem ajuda.
\end{abstract}

Mas há um outro tipo de pessoa acessível a todo conhecimento teórico, e, portanto, também à psicanálise. Essas são pessoas em quem a inteligência irrepreensível parece ter sido apartada de seus impulsos instintivos. Tais pessoas são capazes de pensar sobre as coisas até o limite da conclusão lógica, mas não aplicam os resultados de seu pensamento a seu próprio comportamento ${ }^{5}$.

Como somos todos um pouco saudáveis, um pouco neuróticos e um tanto resistentes, podemos tomar a fala do Homem dos Lobos como um guia para nos levar pelo convite à leitura, sem abandoná-la impulsivamente, quando ela parecer ferir nossa vaidade ou demonstrar que, para desenvolver nosso trabalho, precisamos de ajuda, de parceria, da companhia de um outro. Como diz Foucault, trata-se de tarefa corajosa enfrentar "o que pode ser mudado no seu próprio pensamento, através do exercício de um saber que nos é estranho" (FOUCAULT, 1988, p.13). Por fim, inspiradas por tais autores, apostamos que a reflexão aqui proposta não será estancada pela inteligência irrepreensível dos leitores, e será

\footnotetext{
${ }^{4}$ Nome dado por Freud a seu paciente Sergei Konstantinovitch Pankejeff, que inspirou, entre outros, o artigo "História de uma neurose infantil (O Homem dos Lobos)" (FREUD, [1914]1964a).

${ }^{5}$ No original: "We were talking about how hard it is for a healthy person to accept the principles of Freud's teaching, as they wound his vanity. It is different for the neurotic, who has, in the first place, experienced in his own person the force and aims of his unconscious drives, and, secondly, in submitting to analytic therapy, has acknowledge his inability to manage without help.
}

But there is another type of person accessible to all theoretical knowledge, and therefore also to psychoanalysis. These are the persons whose unimpeachable intelligence seems to be cut off from their instinctive drives. Such persons are capable of thinking things through to the last logical conclusion, but they do not apply the results of this thinking to their own behaviour".

(C) ETD- Educação Temática Digital Campinas, SP $\quad$ v.21 $\quad$ n.2 $\quad$ p.285-287 abr./jun. 2019 
capaz de transformar profundamente a relação do sujeito com ele próprio e de construir uma ética generosa e amorosa com o outro.

\section{REFERÊNCIAS}

BION, W. R. Two papers: The Grid and Caesura. Rio de Janeiro: Imago, 1977.

FOUCAULT, M. História da sexualidade. Rio de Janeiro: Graal, 1988. v. 2.

FREUD, S. An infantile neurosis [1914]. In: FREUD, S. The Standard Edition of the Complete Psychological Works of Sigmund Freud: An infantile neurosis and other works (v. XVII [19171919]). London: Hogarth Press; Institute of Psycho-analysis, 1964a.

FREUD, S. The 'Uncanny' [1919]. In: FREUD, S. The Standard Edition of the Complete Psychological Works of Sigmund Freud: An infantile neurosis and other works (v. XVII [19171919]). London: Hogarth Press; Institute of Psycho-analysis, 1964b.

FREUD, S.; ANDREAS-SALOMÉ, L. Correspondência completa Freud/Lou Andreas-Salomé. Rio de Janeiro: Imago, 1975.

GARDINER, M. My recollections of Sigmund Freud. In: GARDINER, M. The Wolf-Man and Sigmund Freud. London: Hogarth Press, 1973. p. 135-152. 